\title{
ORIGINAL ARTICLE \\ Within- and among-population impact of genetic erosion on adult fitness-related traits in the European tree frog Hyla arborea
}

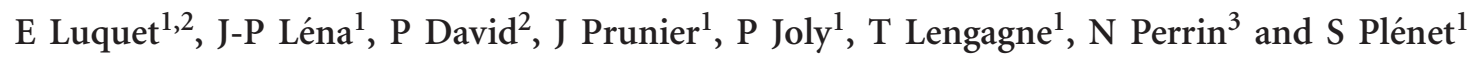 \\ Assessing in wild populations how fitness is impacted by inbreeding and genetic drift is a major goal for conservation biology. \\ An approach to measure the detrimental effects of inbreeding on fitness is to estimate correlations between molecular variation \\ and phenotypic performances within and among populations. Our study investigated the effect of individual multilocus \\ heterozygosity on body size, body condition and reproductive investment of males (that is, chorus attendance) and females (that \\ is, clutch mass and egg size) in both small fragmented and large non-fragmented populations of European tree frog (Hyla \\ arborea). Because adult size and/or condition and reproductive investment are usually related, genetic erosion may have \\ detrimental effects directly on reproductive investment, and also on individual body size and condition that in turn may affect \\ reproductive investment. We confirmed that the reproductive investment was highly size-dependent for both sexes. Larger \\ females invested more in offspring production, and larger males attended the chorus in the pond more often. Our results did \\ not provide evidence for a decline in body size, condition and reproductive effort with decreased multilocus heterozygosity both \\ within and among populations. We showed that the lack of heterozygosity-fitness correlations within populations probably \\ resulted from low inbreeding levels (inferior to ca. $20 \%$ full-sib mating rate), even in the small fragmented populations. The \\ detrimental effects of fixation load were either low in adults or hidden by environmental variation among populations. These \\ findings will be useful to design specific management actions to improve population persistence.
}

Heredity (2013) 110, 347-354; doi:10.1038/hdy.2012.110; published online 19 December 2012

Keywords: amphibians; heterozygosity; habitat fragmentation; fitness; inbreeding; reproductive investment

\section{INTRODUCTION}

Understanding the proximal causes leading to population declines and extinctions is a major goal in conservation biology (Frankham et al., 2002; Keller and Waller, 2002). Fragmented populations are threatened to decline mainly because reduction in size and increasing isolation cause demographic stochasticity and genetic erosion (broadly defined as the reduction of genetic diversity due to genetic drift and inbreeding). Inbreeding and genetic drift increase the expression of recessive deleterious mutations and their fixation rate, respectively (Hedrick, 2001). As a consequence, genetically eroded populations are assumed to show a reduced mean fitness. Numerous studies demonstrated in various taxa a reduction in fitness caused by genetic erosion (for example, Rowe and Beebee, 2003; Reed, 2005; Ficetola et al., 2007; Johansson et al., 2007; Angelone, 2010; Luquet et al., 2011b), but they rarely unraveled the genetic process behind this reduction (but see Luquet et al., 2011a). An approach to measure the detrimental effects of genetic erosion on fitness is to estimate correlations between molecular variation and phenotypic performances within and among populations (see Szulkin et al., 2010; Luquet et al., 2011a). Considering both within- and among-population levels is useful to determine the relative importance of genetic processes acting in fragmented populations, and ultimately devise conservation policies (Jaquiéry et al., 2009; Luquet et al., 2011a).
At the among-population level, correlations between genetic diversity estimators and average fitness traits across a range of populations can reveal 'ambient inbreeding' shared by all members of the population (Saccheri et al., 1998; Reed and Frankham, 2003; Luquet et al., 2011a, 2012). The main mechanism behind this effect is the fixation of mildly deleterious alleles by random genetic drift (that is, fixation load; Whitlock et al., 2000; Glemin et al., 2003). It is often this fixation load that poses a serious threat to the persistence of populations because more and more mutations become fixed as population fragmentation increases (Glemin et al., 2003; Whitlock, 2003).

At the within-population level, individual multilocus heterozygosity can be correlated to fitness traits (heterozygosity-fitness correlations or HFCs; David, 1998; Hansson and Westerberg, 2002; Coltman and Slate, 2003; Chapman et al., 2009; Szulkin et al., 2010). Theory predicts that HFC arises if there are differences in pedigree inbreeding (that is, the degree of relatedness between parents) among individuals within populations (Ohta, 1971; Ohta and Cockerham, 1974; Bierne et al., 2000; Tsitrone et al., 2001). HFC should be stronger within populations exhibiting high variance in individual pedigree inbreeding and phenotypic performances, such as recently fragmented populations (Grueber et al., 2008). If genetic erosion is prolonged and extreme, however, HFC becomes harder to detect as genetic variance is eroded and deleterious alleles go to fixation.

\footnotetext{
1UMR 5023 Ecologie des Hydrosystèmes Naturels et Anthropisés, Université Claude Bernard Lyon1, Université de Lyon, Villeurbanne, France; ${ }^{2}$ Centre d’Ecologie Fonctionnelle et Evolutive UMR 5175, Montpellier, France and ${ }^{3}$ Département d'Ecologie et Evolution, Université de Lausanne, Lausanne, Switzerland 
Body size, body condition and reproductive investment are good candidates for revealing genetic erosion effects on the adult life stage since they are closely linked to fitness and likely to involve many different loci that carry deleterious recessive mutations. Body size reflects age (especially in organisms with indeterminate growth) as well as the past growth trajectory of the individual (David et al., 1995), while body condition (usually represented by a function of body mass standardized by body size) represents the nutritional status of organisms, depending more on the recent environmental conditions. Considering both body size and body condition is important to determine if genetic erosion affects growth trajectory or individual abilities to get a good nutritional status. The reproductive investment represents energy allocated to reproduction, usually through mate attraction (secondary sexual traits) or male-male competition in males and offspring production in females. This investment depends on individual size and body condition (for example, Kotiaho et al. 2001; Brandt and Greenfield, 2004; Rasanen et al., 2008). Reduced genetic quality due to genetic erosion may therefore have direct detrimental effects on reproductive investment as well as indirect effects through body size and condition.

As with many amphibians in Europe, European tree frog (Hyla arborea) populations have experienced a substantial reduction in size and an increasing isolation during the past decades, and several studies have already revealed genetic erosion in small and isolated populations (Andersen et al., 2004; Angelone and Holderegger, 2009; Broquet et al., 2010). In this context, we investigated the relationship between multilocus heterozygosity at 15 microsatellite loci and body size, body condition and reproductive investment of tree frog adults within and among four wild populations: two were small isolated populations and two others were larger and non-fragmented. Luquet et al. (2011a) previously revealed during the early larval period (i) consistent differences in heterozygosity and larval fitness-related traits in these same four populations reared in a laboratory setting and (ii) an increase in larval performance in heterozygous progenies from crosses between two small isolated populations. The resulting positive relationships between genetic diversity and fitness traits among populations provided a sound groundwork to investigate such correlations in the wild on the adult stage in these populations.

We specifically addressed the following question: are body size, body condition and reproductive investment (measured as chorus attendance for males and clutch mass and egg size for females) impacted by genetic erosion within and among populations? As Luquet et al. (2011a) observed an effect of the fixation load during the larval period but did not detect inbreeding within the two small isolated populations, we expected to observe nonsignificant HFCs within populations (that is, no inbreeding depression), including fragmented ones and positive relationships between genetic diversity and adult fitness traits among the four populations (that is, fixation load effect).

\section{MATERIALS AND METHODS}

\section{Studied populations}

Source H. arborea populations are located in southeastern France (Table 1; see Luquet et al. (2011b) for more details on the studied populations). Two populations are relatively large, located in a non-fragmented landscape, and previously shown to be relatively more genetically variable (Planches $\mathrm{P}$ and Mépieu M geographically distant by $8 \mathrm{~km}$; Table 1), while two others are relatively smaller, located in a fragmented landscape, isolated and genetically eroded (Cheylas C and Laissaud L geographically distant by $10 \mathrm{~km}$; Table 1). As shown by Broquet et al. (2010), low habitat connectivity for isolated populations acts as a genetic bottleneck by decreasing effective population size.

\section{Genetic analyses}

The individual genetic variability was estimated using buccal swabs performed on each adult sampled in four populations (method according to Pidancier et al. (2003) and Broquet et al. (2007)). Allelic frequencies were assessed at 15 autosomal microsatellite loci (Ha-A11, Ha-A119, Ha-A127, Ha-A130, Ha-B5R3, Ha-D3R3, Ha-D115, WHA1-20, WHA1-25, WHA1-67, WHA1103, Ha-D-104, Ha-D-106 and Ha-H-116, Ha-A-136; Arens et al., 2000; Berset-Brändli et al., 2008a,b). Several measures of heterozygosity exist but one or the other are often used without theoretical justification. Szulkin et al. (2010) demonstrated that multilocus heterozygosity (MLH) (a simple count of the heterozygous loci) is the most robust measure and does not require standardizations (except to account for a strong variation in genetic diversity among loci; see also Chapman et al. (2009) for discussion). We therefore used MLH as the measure of individual heterozygosity.

\section{Adult sampling and fitness measures}

Males and females from each population were caught at night from 16 April to 12 May 2008 when they converged to breeding areas. In the large connected populations, 34/46 (females/males) and 48/36 individuals were collected in $\mathrm{P}$ and $\mathrm{M}$, respectively (Supplementary Table S1). In both small isolated populations, we maximized sampling effort to obtain 18/57 (females/males) and 50/157 in L and C, respectively (Supplementary Table S1). All individuals were marked with transponders (Nonatec SA) injected subcutaneously in the back before being released to avoid sampling the same individual.

Adult body size and body condition. To estimate body size, we measured the length of the back leg (length between the two metatarsi; precision $0.5 \mathrm{~mm}$ ) of all sampled individuals. Leg length is a more repeatable measurement on adults than the snout-vent length (JP Léna, personal communication) and is often

Table 1 Isolation status, coordinates and genetic properties of the study populations

\begin{tabular}{|c|c|c|c|c|c|c|c|c|c|c|c|c|}
\hline \multirow[t]{2}{*}{ Isolation status } & \multirow[t]{2}{*}{ Population } & \multirow[t]{2}{*}{ Coordinates } & \multirow[t]{2}{*}{$\mathrm{N}$ females } & \multirow[t]{2}{*}{$\mathrm{N}$ alleles } & \multirow{2}{*}{$\begin{array}{l}\text { Allelic } \\
\text { richness }\end{array}$} & \multirow[t]{2}{*}{$\mathrm{H}_{\exp }$} & \multirow[t]{2}{*}{$\mathrm{H}_{o b s}$} & \multirow[t]{2}{*}{$F_{\text {is }}$} & \multicolumn{4}{|c|}{$F_{s t}$} \\
\hline & & & & & & & & & C & $L$ & $\mathrm{P}$ & M \\
\hline Isolated & C & $\begin{array}{l}45^{\circ} 23^{\prime} 46^{\prime \prime} \mathrm{N} \\
5^{\circ} 59^{\prime} 41^{\prime \prime} \mathrm{E}\end{array}$ & $30-50$ & $4.00(0.68)$ & $3.63(0.62)$ & $0.38(0.07)$ & $0.42(0.01)$ & -0.084 & - & 0.0978 & 0.0982 & 0.0949 \\
\hline Isolated & $\mathrm{L}$ & $45^{\circ} 28^{\prime} 18^{\prime \prime} \mathrm{N}, 6^{\circ} 3^{\prime} 51^{\prime \prime} \mathrm{E}$ & $15-25$ & $3.60(0.52)$ & $3.56(0.51)$ & $0.37(0.07)$ & $0.38(0.01)$ & -0.041 & & - & 0.1177 & 0.115 \\
\hline Non-fragmented & $\mathrm{P}$ & $45^{\circ} 44^{\prime} 20^{\prime \prime} N, 5^{\circ} 21^{\prime} 7^{\prime \prime} E$ & $\infty$ & $5.60(0.49)$ & $5.52(0.47)$ & $0.43(0.06)$ & $0.40(0.01)$ & 0.061 & & & - & 0.0197 \\
\hline Non-fragmented & M & $45^{\circ} 44^{\prime} 3^{\prime \prime} N, 5^{\circ} 27^{\prime} 21^{\prime \prime} E$ & $\infty$ & $4.73(0.50)$ & $4.71(0.50)$ & $0.46(0.06)$ & $0.46(0.01)$ & -0.002 & & & & \\
\hline All isolated & & & & $5.13(0.69)$ & $4.78(0.65)$ & $0.39(0.07)$ & $0.41(0.01)$ & -0.024 & & & & \\
\hline All non-fragmented & & & & $6.07(0.57)$ & $6.03(0.57)$ & $0.45(0.06)$ & $0.43(0.01)$ & 0.038 & & & & \\
\hline
\end{tabular}

Abbreviations: $N$ females, estimated number of females; $N$ alleles, number of alleles; $H_{\text {exp }}$, gene diversity; $H_{0 b s}$, observed heterozygosity. .

Fixation index $F_{i s}$ were all nonsignificant and $F_{s t}$ were all significant. The following genetic information were calculated with $F_{\text {stat }} 2.9 .3$ (Goudet, 2001). For more details on genetic characteristics of these populations, see Broquet et al. (2010). 
used to estimate body size in amphibians (for example, Alho et al., 2011). Body condition was estimated as the residual of body mass (measured after egg laying for females; precision $0.1 \mathrm{~g}$ ) against leg length with a $\log -\log$ regression.

Male reproductive investment. We estimated the male reproductive investment only in the isolated $\mathrm{L}$ population. The complex terrestrial habitat of the $\mathrm{C}$ isolated population and the large number of males in P- and M-nonfragmented populations did not allow to capture all males in one night in these populations. We used chorus attendance for each male, that is, the number of nights spent calling at the breeding site, to estimate the male reproductive investment. The chorus attendance is a good proxy for reproductive investment in $H$. arborea because males incur a high metabolic cost while calling to attract females (Grafe and Thein, 2001) and increasing chorus attendance significantly improves male mating success (Friedl and Klump, 2005; Jaquiery et al., 2010). Because males were marked with transponders and released the next day, the first night of capture was not considered to measure chorus attendance. All calling males were sampled each night across all the breeding period (26 nights). We broadcasted a chorus playback to avoid that the calling ceased after male capture or to stimulate the chorus. We stopped the capture session at two o'clock in the morning or later when calling had stopped and pairs in amplexus were not seen for an hour.

Maternal reproductive investment. Since $H$. arborea females lay one clutch per reproductive season and do not dispense parental care, their investment in offspring production is crucial for fitness. A good proxy for investment in offspring production is clutch mass and egg size (Rasanen et al., 2008; Ficetola and De Bernardi, 2009). In each population, immediately after capture, we formed random pairs of males and females in transparent tanks $(17.5 \mathrm{~cm} \times 33$ $\mathrm{cm} \times 18.5 \mathrm{~cm}$ ) filled with pond water and vegetation to obtain a clutch for each female. We used animals only once for reproduction. The number of clutches obtained from each population varied according to the number of females sampled (Supplementary Table S1). Individuals were released $24 \mathrm{~h}$ after mating occurred. As some parts of the clutches were used for other experiments (Luquet et al., 2011b), clutch mass was indirectly estimated by the difference of female body mass before and after laying. To estimate the mean egg size per clutch, 20-30 eggs per clutch were sampled within $24 \mathrm{~h}$ after laying (Gosner stage $<12$ ) and were stored in formaldehyde (Rasanen et al., 2008). Each clutch sample was photographed with a digital camera (Olympus Camedia C-2000 Zoom, resolution $1600 \times 1200$ pixels, Center Valley, PA, USA) mounted on a trinocular dissection microscope (Olympus SZXILLD200, Olympus, Center Valley, PA, USA). The images were analyzed using ImageJ (http://rsb.info.nih.gov/ij/index.html) to estimate the egg area. Because egg size and clutch mass were positively correlated $(r=0.36, P<0.001)$, we used clutch mass and the residuals of egg size against clutch mass regression as indicators of maternal reproductive investment.

\section{Statistical analyses}

Power of marker panel. As HFCs emerge from variance in individual inbreeding, it is useful to estimate this variance directly from molecular data. This can be done through the use of $g_{2}$, a parameter that estimates the identity disequilibrium defined as the excess of double heterozygotes at two loci relative to the expectation under random association (that is, covariance in heterozygosity), standardized by average heterozygosity (David et al., 2007). This parameter is central to all models of inbreeding-based HFC as HFC should exist only if $\mathrm{g}_{2}>0$ (Szulkin et al., 2010). We used the RMES software (David et al., 2007) to estimate $g_{2}$ and to test using permutations the null hypothesis that $g_{2}=0$ (alternative hypothesis $g_{2}>0$, expected when there is some variance in inbreeding). In addition, we evaluated the power of our set of markers to detect inbreeding. To that end, we modified RMES to simulate data sets with the same characteristics of our original data sets (number of loci, number of individuals, mean heterozygosity per loci) and various degrees of inbreeding, and in each case we checked how many out of 100 simulations yielded a statistically significant $g_{2}$ at a specified $P$-value threshold. We chose to simulate inbreeding by assuming a given proportion (10, 20 or 30\%) of individuals issued from full-sib mating in the population assuming full-sib mating at equilibrium among generations.
Correlations between molecular variation and phenotypic performances. We performed statistical analyses on quantitative traits (leg length, body condition, clutch mass and residuals of egg size) with linear models. Chorus attendance was analyzed with a generalized linear model using a Poisson error distribution with $\log$ link. In this generalized linear model, overdispersion has been considered by adding an overdispersion parameter.

To test the relative effects of inbreeding and fixation load, we first analyzed the effects of MLH alone on body size, body condition and reproductive investment with all populations pooled (except for males where reproductive investment was only measured in one population). Second, we fitted a model predicting individual phenotypes as a result of the continuous variable MLH and a categorical factor describing the individual origin (C, L, M and P; except for chorus attendance recorded in only one population). Third, we tested the size and/or condition dependence of reproductive efforts by fitting models with both leg length and body condition, either together or separately. The analyses on body size and body condition were performed separately on males and females because of a strong sex effect on this trait (Supplementary Table S2). The analyses on chorus attendance, clutch mass and residuals of egg size accounted for individual leg length as a covariable.

All nonsignificant interactions were excluded in the final models. The analyses were performed using JMP 7.0 (SAS Institute, Cary, NC, USA).

\section{RESULTS}

\section{Variance in inbreeding and power of tests}

All four populations had a positive estimate of $g_{2}$, which was marginally significant only in one of them (M (Table 2), $P=0.05$ ), the other three being nonsignificant. Our power calculations showed that we had reasonable power (between 0.5 and 0.8 ) to detect a level of inbreeding that corresponds roughly to $20 \%$ full-sib mating in all four populationsthis is approximately the level that corresponded to the only significant value obtained in population M. Higher levels of inbreeding would have been detected with a very high probability ( 0.9 on average).

\section{Correlations between molecular variation and phenotypic performances}

Neither male or female leg length nor condition was associated with MLH, in the whole pooled data set (male leg length: F1, 293 $=0.099$, $P=0.754$; female leg length: $\mathrm{F} 1,147=1.665, P=0.199$; male condition: $\mathrm{F} 1,293=0.114, P=0.736$; female condition: $\mathrm{F} 1,137=0.009$, $P=0.924$ ) and within each population (no significant MLH $\times$ population interaction; male leg length: $F 3,287=0.298, P=0.826$; female leg length: F3, $141=0.212, P=0.888$; male condition: $F 3$, $287=1.476, P=0.221$; female condition: $\mathrm{F} 3,131=1.582, P=0.197$; Figure 1). Leg length and body condition of males and females significantly varied among populations (Supplementary Table S2 and Supplementary Table S3 for coefficients).

Table 2 Observed values of $g_{2}$ and power of the marker panel to detect various levels of inbreeding

Populations

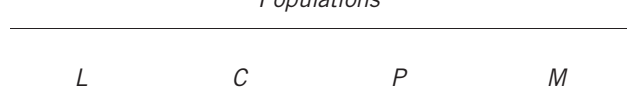

Observed $g_{2}(P$-value $) \quad 0.006(0.31) \quad 0.005(0.23) \quad 0.008(0.26) \quad 0.019(0.05)$

$\begin{array}{cccll}\text { Power of test under FSM rate (expected } \mathrm{g}_{2} \text { ) } & & & \\ 0.1(0.007) & 0.2 & 0.57 & 0.16 & 0.2 \\ 0.2(0.018) & 0.52 & 0.79 & 0.54 & 0.64 \\ 0.3(0.032) & 0.74 & 1 & 0.83 & 0.92\end{array}$

Abbreviation: FSM, full-sib mating.

The power is the probability to have a significant $g_{2}$ parameter $(P<0.05)$ for each population assuming recurrent FSM at equilibrium (rates 10, 20 and $30 \%$ ) from 100 simulations (RMES software; David et al., 2007). 

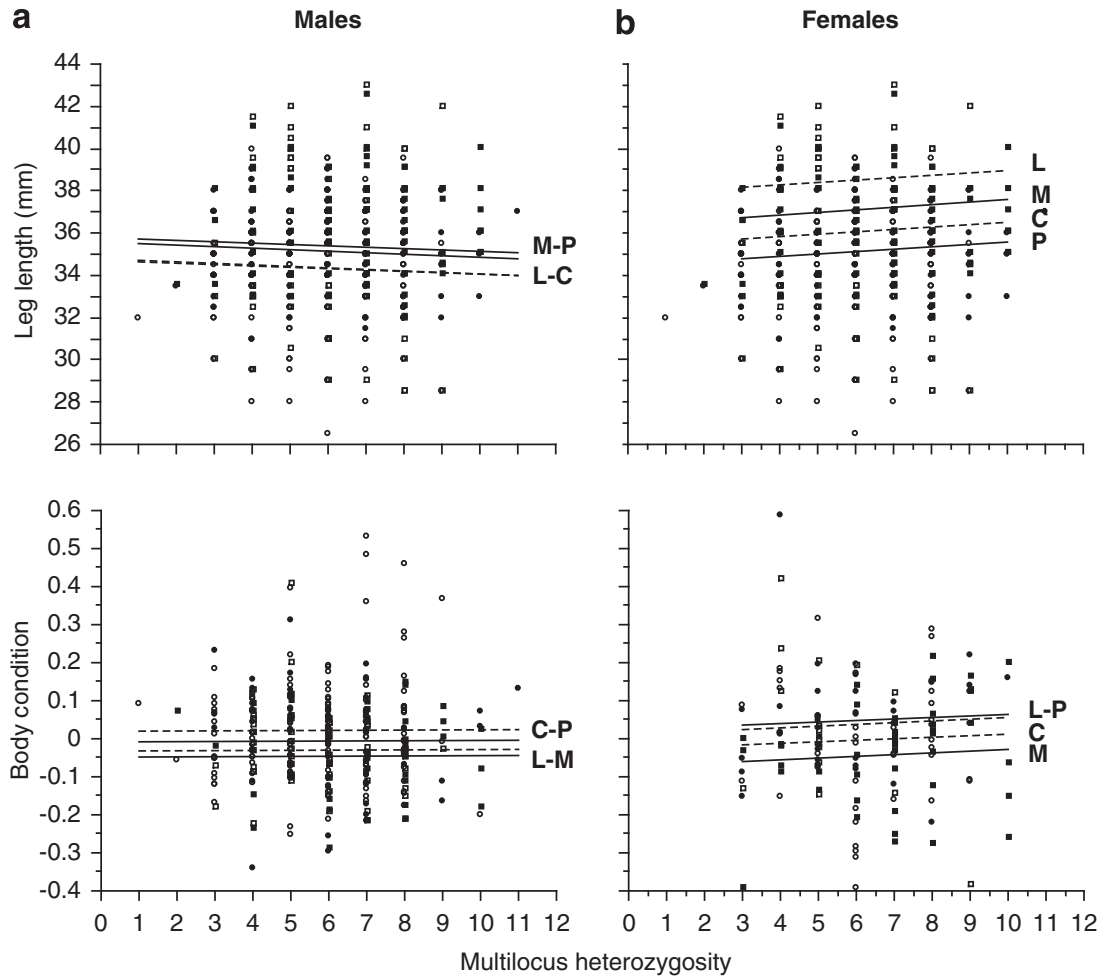

Figure 1 The relationships between leg length, body condition and multilocus heterozygosity of (a) males and (b) females in the four populations. Dashed and full lines represent, respectively, individuals from isolated (C, open circle; L, open square) and connected ( $P$, filled circle; M, filled square) populations. Points are individuals.

Chorus attendance of males from the $\mathrm{L}$ population globally increased with leg length (low for small leg length and highly variable among males with large leg length; $\chi^{2} 1=7.75, P=0.005$; Figure $2 \mathrm{a}$ ). There was no significant relationship between chorus attendance and male condition $\left(\chi^{2} 1=1.47, P=0.225\right.$; Figure $\left.2 \mathrm{a}\right)$

Clutch mass was positively associated with female leg length in the four populations, while a positive association between clutch mass and body condition was found only in the L-fragmented and M-nonfragmented populations (significant female condition $\times$ population interaction; Figure 2b, Tables $3 \mathrm{a}$ and $\mathrm{b}$ and Supplementary Table S4 for coefficients). Egg size significantly increased with female leg length and condition in the four populations (Figure $2 \mathrm{~b}$ and Tables $3 \mathrm{a}$ and b). However, unlike leg length, body condition was not a good predictor of female reproductive investment; female condition did not explain a significant amount of variance when leg length was present in the model (Table 3c).

Although chorus attendance was highly variable among males from the $\mathrm{L}$ isolated population, from 1 to 10 nights, this male reproductive investment was not correlated with MLH (MLH: $\chi^{2} 1=0.054$, $P=0.816$; male leg length: $\chi^{2} 1=7.475, P=0.006$; Figure $\left.3 \mathrm{a}\right)$. Similarly, clutch mass and egg size were not affected by MLH in any of the models (Figure $3 \mathrm{~b}$ and Table $3 \mathrm{~d}$ ). This was true for all populations (nonsignificant $\mathrm{MLH} \times$ population interaction; Table $3 \mathrm{e}$ ).

\section{DISCUSSION}

Our study investigated how genetic erosion (that is, reduction in genetic diversity due to inbreeding and genetic drift) in fragmented populations could impact adult size, condition and reproductive investment of males and females. None of these traits (size, condition and reproductive investment) were positively correlated with multilocus heterozygosity, be it within or among populations.
Lack of HFCs within populations: methodological limitations or low inbreeding levels

The lack of HFCs on adult traits within populations (especially in fragmented ones) can have several non-exclusive origins. First, if variance in inbreeding levels within populations is too low, HFC disappears both because inbreeding explains a smaller proportion of the variance in fitness expressed in the population, and because marker heterozygosity becomes more loosely correlated with inbreeding (Pemberton, 2004). Second, HFC and inbreeding might be present, but the number and genetic diversity of the markers used might be insufficient to capture them adequately. Third, the traits studied may be relatively insensitive to inbreeding. The first and second hypotheses can be evaluated using our estimates of $g_{2}$ and associated simulations. The $g_{2}$ values in our populations were positive but small, suggesting very moderate levels of inbreeding, equivalent to $10 \%$ full-sib mating, except in the $M$ population (20\%). Our simulations showed that our set of 15 markers was likely to detect inbreeding levels equivalent to $20 \%$ full-sib mating or more (Table 2). It is therefore probable that inbreeding levels were truly low in these populations, even the small ones, which partly explains why HFCs were not detected. Lack of HFC within populations was also found in a previous study on larval traits in the same four populations (Luquet et al., 2011a), using a more powerful estimate of inbreeding (that is, average expected heterozygosity in offspring from parental genotypes; Primmer et al., 2003).

Low frequency of matings between related individuals is a possible cause of low overall impacts of inbreeding depression. Importantly, the European tree frog exhibits complex mechanisms of female mate choice (for example, Jaquiery et al., 2010) that could lead to inbreeding avoidance, especially in small fragmented populations (Neff and Pitcher, 2005). 

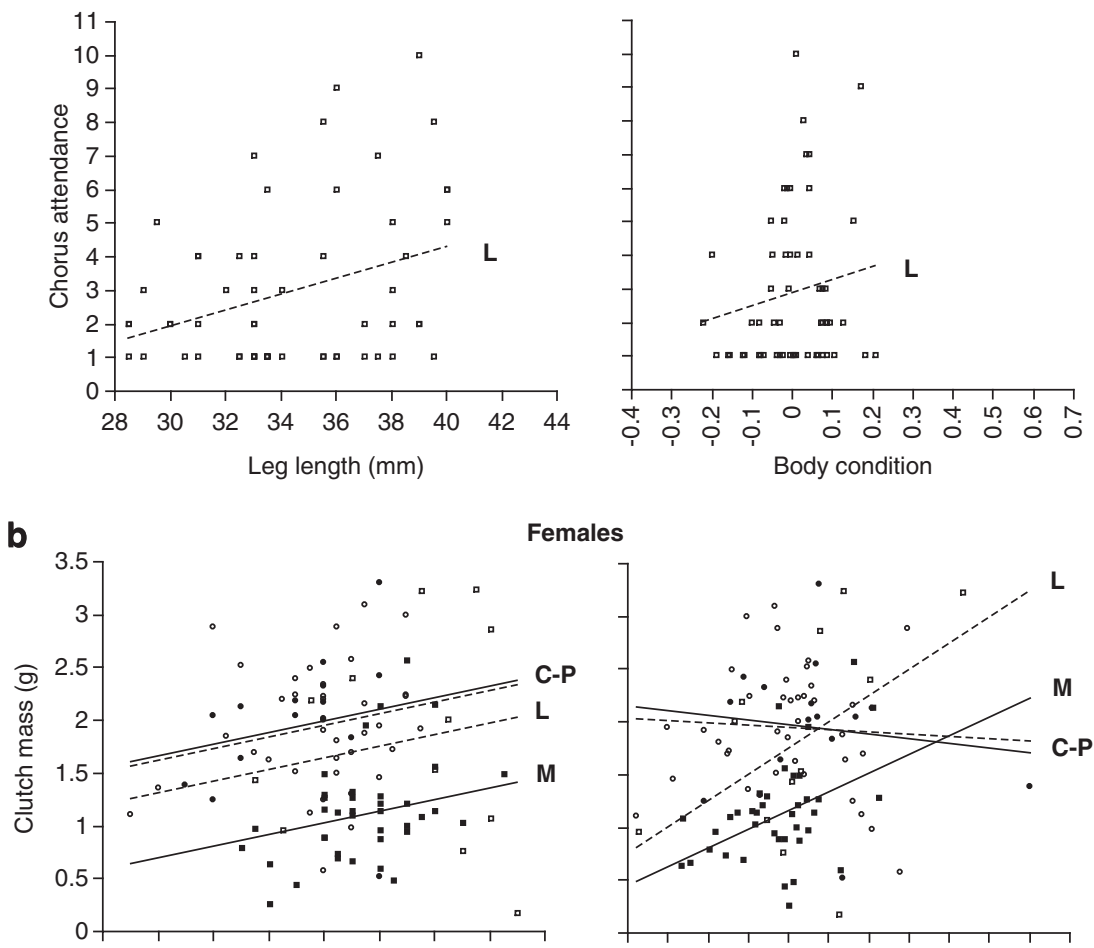

Females
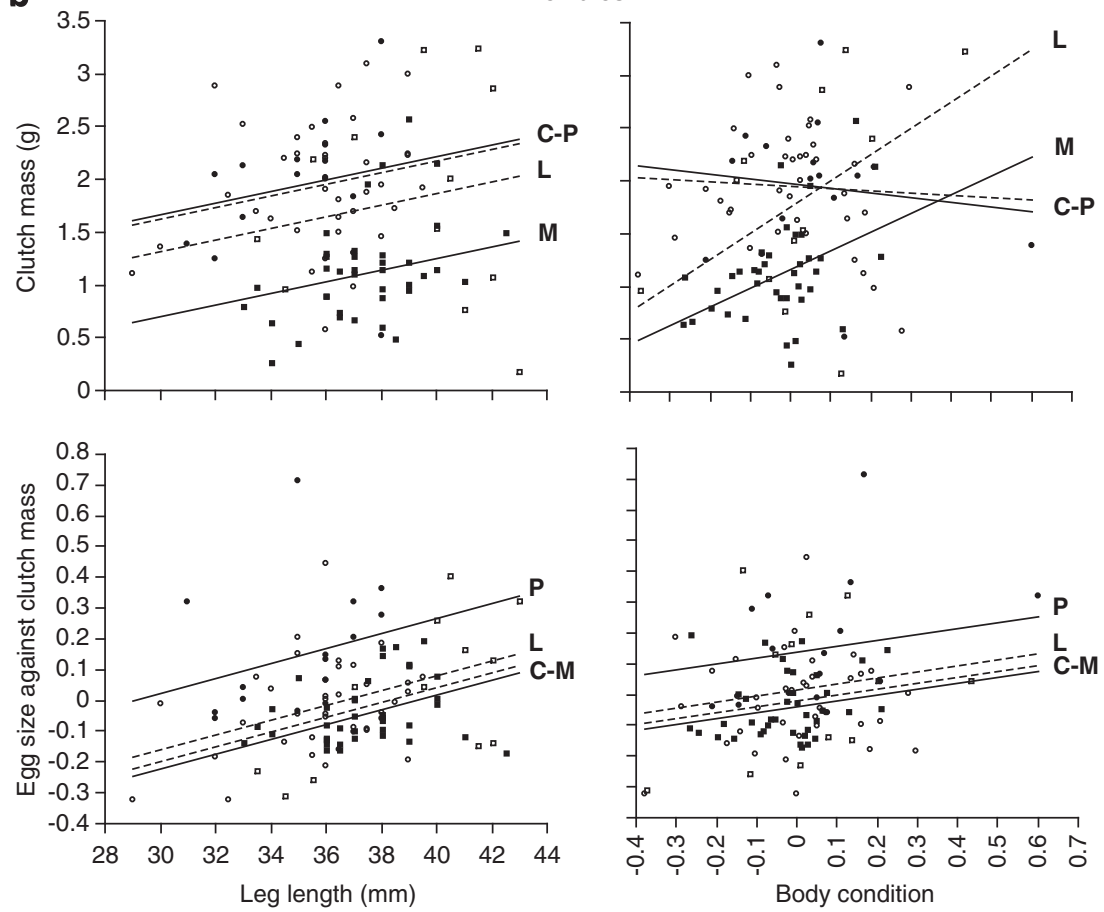

Figure 2 The relationships between reproductive efforts and leg length or body condition of (a) males (chorus attendance) and (b) females (clutch mass, egg size) in the four populations. Dashed and full lines represent, respectively, individuals from isolated (C, open circle; L, open square) and connected ( $P$, filled circle; $M$, filled square) populations. Points are individuals.

The low HFC within populations could also be due to the lack or weakness of the segregational load affecting the traits under study. Early-expressed traits such as embryonic development and egg survival are often more affected by segregating deleterious alleles (and inbreeding depression) than adult traits. Mutations that disrupt basic metabolic or developmental processes when in the homozygous state are often semilethals and the animals die before reaching the adult stage; hence, they cannot contribute to HFC. Ficetola et al. (2010) demonstrated in a small and isolated population of the threatened frog Rana latastei that rapid selection against inbred individuals decreased the inbreeding coefficient $\left(\mathrm{F}_{\mathrm{is}}\right)$ and increased heterozygosity between hatching and metamorphosis. Such selection against unfit genotypes along the life cycle should decrease the phenotypic variance in aging cohorts, which makes the HFC harder to detect (David, 1998; see example in David et al. (1997)). The phenotypic variance $\left(\mathrm{CV}^{2}\right)$ was indeed low within populations (ca. $<5 \%$ except for clutch mass; see Supplementary Table S2) that confirms a low level of inbreeding depression in the traits under study (Waller et al., 2008).

\section{Genetic diversity-mean fitness trait correlations among populations}

Across the range of populations, genetic diversity was not related to average adult fitness traits measured in the wild, which contrasted with the positive relationships detected between average expected heterozygosity in offspring and average larval fitness traits (Luquet et al., 2011a). The effects of fixed deleterious recessive alleles previously revealed during the larval stage were lacking or were not detected in adults. This difference may be explained by three hypotheses. 
Table 3 Linear model analyses of variance for clutch mass and egg size (residuals of egg size against clutch mass) on (a) female leg length and population origin, (b) female condition (that is, residuals of body mass against leg length log-log regression) and population origin, (c) female leg length, condition and population origin, (d) MLH and female leg length and (e) MLH, female leg length and population origin

\begin{tabular}{|c|c|c|c|c|c|c|c|c|}
\hline & \multicolumn{4}{|c|}{ Clutch mass } & \multicolumn{4}{|c|}{ Residuals of egg size against clutch mass } \\
\hline & Num. d.f. & Den. d.f. & $F$ & P-value & Num. d.f. & Den. d.f. & $F$ & P-value \\
\hline \multicolumn{9}{|l|}{ (a) } \\
\hline Female leg length & 1 & 98 & 4.515 & 0.036 & 1 & 98 & 14.275 & $<0.001$ \\
\hline $\begin{array}{l}\text { Population } \\
\text { (b) }\end{array}$ & \multicolumn{7}{|c|}{ (b) } & $<0.001$ \\
\hline Female condition & 1 & 95 & 5.059 & 0.027 & 1 & 98 & 3.508 & 0.064 \\
\hline Population & 3 & 95 & 12.67 & $<0.001$ & 3 & 98 & 4.934 & 0.003 \\
\hline $\begin{array}{l}\text { Female condition } \times \text { pop. } \\
\text { (c) }\end{array}$ & 3 & 95 & 3.198 & 0.027 & & & & \\
\hline Female leg length & 1 & 97 & 4.326 & 0.040 & 1 & 97 & 14.079 & $<0.001$ \\
\hline Female condition & 1 & 97 & 2.659 & 0.106 & 1 & 97 & 3.426 & 0.067 \\
\hline $\begin{array}{l}\text { Population } \\
\text { (d) }\end{array}$ & 3 & 97 & 14.833 & $<0.001$ & 3 & 97 & 8.246 & $<0.001$ \\
\hline Female MLH & 1 & 100 & 0.220 & 0.639 & 1 & 100 & 0.877 & 0.351 \\
\hline $\begin{array}{l}\text { Female leg length } \\
\text { (e) }\end{array}$ & 1 & 100 & 0.581 & 0.810 & 1 & 100 & 4.817 & 0.031 \\
\hline Female MLH & 1 & 97 & 0.608 & 0.437 & 1 & 97 & 0.103 & 0.749 \\
\hline Female leg length & 1 & 97 & 4.449 & 0.037 & 1 & 97 & 9.129 & $<0.001$ \\
\hline Population & 3 & 97 & 16.088 & $<0.001$ & 3 & 97 & 14.176 & $<0.001$ \\
\hline
\end{tabular}

Abbreviations: d.f., degrees of freedom; MLH, multilocus heterozygosity; pop., population.

Nonsignificant MLH $\times$ population interaction has been removed of the final models. Estimates and standard errors are presented in the Appendix (Supplementary Table S4).

Bold values indicate significant effects.
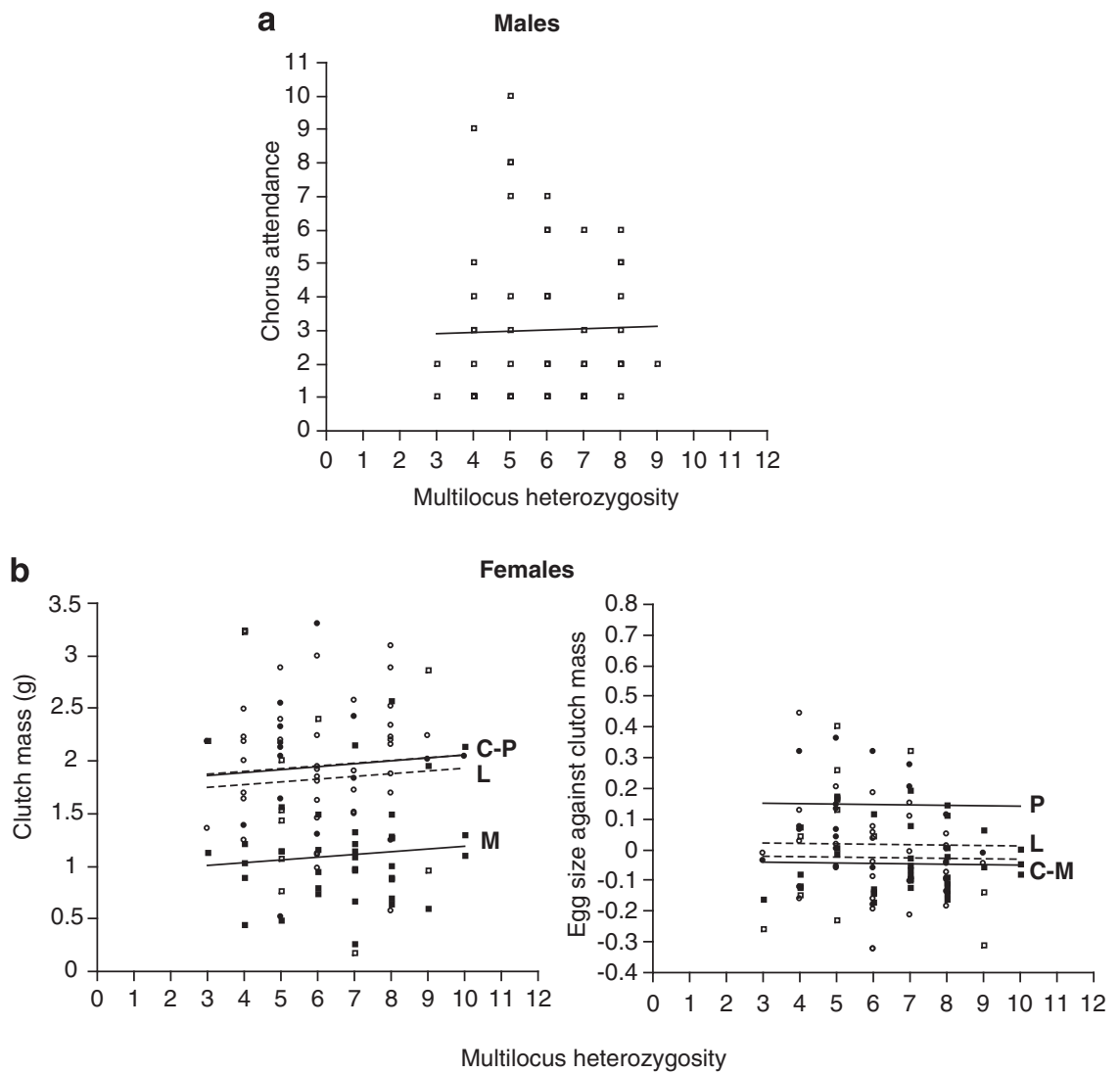

Figure 3 The relationships between reproductive efforts and multilocus heterozygosity of (a) males (chorus attendance) in the L-fragmented population and (b) females (clutch mass, egg size) in the four populations. Dashed and full lines represent, respectively, individuals from isolated (C, open circle; L, open square) and connected (P, filled circle; M, filled square) populations. Points are individuals. 
First, the expression of fixed deleterious alleles can be specific to a life stage or an environment (Ouborg et al., 2010). Especially in species exhibiting complex life cycle like amphibians, the gene pools expressed during larval and adult stages, in aquatic and terrestrial habitats, respectively, can have different fixation loads and therefore different detrimental effects (Husband and Schemske, 1996; Koelewijn et al., 1999; Escobar et al., 2008).

Second, in this study, the adult traits were measured on wild adult individuals varying in age and experiencing different environmental conditions, while in Luquet et al. (2011a), the larval traits came from laboratory experiment in controlled conditions. Environmental variations or differences in age-structure among populations may override the genetic effects on phenotypes (Slate and Pemberton, 2006; Szulkin et al., 2010; Luquet et al., 2011a). Our results support this idea. Reproductive investment was highly size-dependent (that is, larger males and females were able to invest more in reproduction), while the effect of body condition was not significant when body size accounted for. This suggests that reproductive investment was more dependent on the age of individuals and their past growth trajectory (which affect body size) than on recent environmental conditions (which affect current nutritional status and body condition). Moreover, the significant differences in average body size, body condition and reproductive investment among populations were not related to the fragmentation status, for example, females of the L-isolated and P-non-fragmented populations had similar body condition and were both larger than those in the remaining two populations (one isolated and one non-fragmented; Supplementary Tables S2 and S3). Ethical considerations prevented us from performing skeletochronology (which requires toe clipping) to estimate age of individuals. Several environmental factors could be responsible to these variations among populations, but determining these factors was beyond the scope of this study. A challenging experiment would be to compare in controlled conditions the detrimental effects of fixation loads at different life stages from embryos to adults on the same cohorts (see Escobar et al., 2008).

\section{CONCLUSION}

Examining how fitness in wild populations is impacted by inbreeding and genetic drift is a major goal for conservation biology. Our study showed how it can be a difficult challenge in the wild when individuals have experienced different environmental conditions. The relationships between multilocus heterozygosity and adult fitness traits that we investigated within and among populations were not significant; however, it is important to publish such negative results in this field because it is likely to suffer from a publication bias. The lack of relationships is as interesting as positive correlations because both can represent a biological reality. Here, we showed that the lack of HFCs within populations probably resulted from low inbreeding levels (inferior to our marker panel resolution, that is, $20 \%$ full-sib mating rate), even in the small fragmented populations. The detrimental effects of fixation load were either low in adults or hidden by environmental variation among populations and further work is needed to unravel the relative effects of genetic and environmental variations on adult phenotypic variation. In a conservation perspective, our study, together with our previous study on tadpoles (Luquet et al., 2011a), highlighted that these populations are more likely to lose fitness from the expression of fixation load during the larval stage than from within-population variation in inbreeding. These findings will be useful to design specific management actions to improve population persistence.

\section{DATA ARCHIVING}

Data have been submitted to Dryad repository: doi:10.5061/ dryad.p0d83.

\section{CONFLICT OF INTEREST}

The authors declare no conflict of interest.

\section{ACKNOWLEDGEMENTS}

This research was funded by the ANR Colapse (Grant No. BLAN06-1-158238) and the Conseil Général de l'Isère. We are grateful to three anonymous referees for helpful comments on the manuscript. Special thanks to Benjamin Galiot and Pierre Sagnes for their precious help and work to measure egg size. We thank Julien Chiaffi for the support in the field and laboratory. We also thank Isabelle Drillat from the Office National des Forêts, André Miquet from the Conservatoire du Patrimoine Naturel de Savoie and the staff of Lo Parvi and Avenir for their support in the field. This study was conducted with the approval of Préfecture de l'Isère (decision 2007-03328), in accordance with the current laws in France and under the approval of the Direction of Veterinary Services (DSV permit no. 692661232).

Alho JS, Herczeg G, Laugen AT, Rasanen K, Laurila A, Merila J (2011). Allen's rule revisited: quantitative genetics of extremity length in the common frog along a latitudinal gradient. J Evol Biol 24: 59-70.

Andersen LW, Fog K, Damgaard C (2004). Habitat fragmentation causes bottlenecks and inbreeding in the European tree frog (Hyla arborea). Proc $R$ Soc Ser $B$ 271: 1293-1302.

Angelone S (2010). Are differences in fitness traits related to genetic clusters? An empirical test on the European tree frog. Biol Conserv 143: 471-478.

Angelone S, Holderegger R (2009). Population genetics suggests effectiveness of habitat connectivity measures for the European tree frog in Switzerland. J Appl Ecol 46: 879-887.

Arens P, Van't Westende W, Bugter R, Smulders MJM, Vosman B (2000). Microsatellite markers for the European tree frog Hyla arborea. Mol Ecol 9: 1944-1946.

Berset-Brändli L, Jaquiéry J, Broquet T, Perrin N (2008a). Isolation and characterization of microsatellite loci for the European tree frog (Hyla arborea). Mol Ecol Res 8: 1095-1097.

Berset-Brändli L, Jaquiéry J, Broquet T, Ulrich Y, Perrin N (2008b). Extreme heterochiasmy and nascent sex chromosomes in European tree frogs. Proc $R$ Soc Ser $B$ 275: 1577-1585.

Bierne N, Tsitrone A, David P (2000). An inbreeding model of associative overdominance during a population bottleneck. Genetics 155: 1981-1990.

Brandt LSE, Greenfield MD (2004). Condition-dependent traits and the capture of genetic variance in male advertisement song. J Evol Biol 17: 821-828.

Broquet T, Angelone S, Jaquiéry J, Joly P, Léna J-P, Lengagne T et al. (2010). Genetic bottlenecks driven by population disconnection. Conserv Biol 24: 1596-1605.

Broquet T, Berset-Brändli L, Emaresi G, Fumagalli L (2007). Buccal swabs allow efficient and reliable microsatellite genotyping in amphibians. Conserv Genet 8: 509-511.

Chapman JR, Nakagawa S, Coltman DW, Slate J, Sheldon BC (2009). A quantitative review of heterozygosity-fitness correlations in animal populations. Mol Ecol 18: 2746-2765.

Coltman DW, Slate J (2003). Microsatellite measures of inbreeding: a meta-analysis. Evolution 57: 971-983.

David P (1998). Heterozygosity-fitness correlations: new perspectives on old problems. Heredity 80: 531-537.

David P, Delay B, Berthou P, Jarne P (1995). Alternative models for allozyme-associated heterosis in the marine bivalve Spisula ovalis. Genetics 139: 1719-1726.

David P, Delay B, Jarne P (1997). Heterozygosity and growth in the marine bivalve Spisula ovalis: testing alternative hypotheses. Genet Res 70: 215-223.

David P, Pujol B, Viard F, Castella V, Goudet J (2007). Reliable selfing rate estimates from imperfect population genetic data. $\mathrm{Mol}$ Ecol 16: 2474-2487.

Escobar JS, Nicot A, David P (2008). The different sources of variation in inbreeding depression, heterosis and outbreeding depression in a metapopulation of Physa acuta. Genetics 180: 1593-1608.

Ficetola GF, De Bernardi F (2009). Offspring size and survival in the frog Rana latastei: from among-population to within-clutch variation. Biol J Linn Soc 97: 845-853.

Ficetola GF, Garner TWJ, De Bernardi F (2007). Genetic diversity, but not hatching success, is jointly affected by postglacial colonization and isolation in the threatened frog, Rana latastei. Mol Ecol 16: 1787-1797.

Ficetola GF, Garner TWJ, Wang J, De Bernardi F (2010). Rapid selection against inbreeding in a wild population of a rare frog. Evol App/ 4: 30-38.

Frankham R, Ballou JD, Briscoe DA (2002). Introduction to Conservation Genetics. Cambridge University Press: Cambridge.

Friedl TWP, Klump GM (2005). Sexual selection in the lek-breeding European treefrog: body size, chorus attendance, random mating and good genes. Anim Behav 70: 1141-1154. 
Glemin S, Ronfort J, Bataillon T (2003). Patterns of inbreeding depression and architecture of the load in subdivided populations. Genetics 165: 2193-2212.

Goudet J (2001). FSTAT, A Program to Estimate and Test Gene Diversities and Fixation Indices (version 2.9.3). Université de Lausanne: Switzerland.

Grafe TU, Thein J (2001). Energetics of calling and metabolic substrate use during prolonged exercise in the European treefrog Hyla arborea. J Comp Physiol B 171: 69-76.

Grueber CE, Wallis GP, Jamieson IG (2008). Heterozygosity-fitness correlations and their relevance to studies on inbreeding depression in threatened species. $\mathrm{Mol}$ Ecol 17 3978-3984.

Hansson B, Westerberg L (2002). On the correlation between heterozygosity and fitness in natural populations. Mol Ecol 11: 2467-2474.

Hedrick PW (2001). Conservation genetics: where are we now? Trends Ecol Evol 16 629-636.

Husband BC, Schemske DW (1996). Evolution of the magnitude and timing of inbreeding depression in plants. Evolution 50: 54-70.

Jaquiery J, Broquet T, Aguilar C, Evanno G, Perrin N (2010). Good genes drive female choice for mating partners in the lek-breeding European treefrog. Evolution 64: 108-115.

Jaquiéry J, Guillaume F, Perrin N (2009). Predicting the deleterious effects of mutation load in fragmented populations. Conserv Biol 23: 207-218.

Johansson M, Primmer CR, Merila J (2007). Does habitat fragmentation reduce fitness and adaptability? A case study of the common frog (Rana temporaria). Mol Ecol 16 2693-2700.

Keller LF, Waller DM (2002). Inbreeding effects in wild populations. Trends Ecol Evol 17: 230-241.

Koelewijn HP, Koski V, Savolainen O (1999). Magnitude and timing of inbreeding depression in Scots pine (Pinus sylvestris L.). Evolution 53: 758-768.

Kotiaho JS, Simmons LW, Tomkins JL (2001). Towards a resolution of the lek paradox. Nature 410: 684-686.

Luquet E, David P, Lena JP, Joly P, Konecny L, Dufresnes C et al. (2011a). Heterozygosityfitness correlations among wild populations of European tree frog (Hyla arborea) detect fixation load. Mol Ecol 20: 1877-1887.

Luquet E, Garner TWJ, Léna J-P, Bruel C, Joly P, Lengagne T et al. (2012). Genetic erosion in wild populations makes resistance to a pathogen more costly. Evolution 66: 1942-1952.

Luquet E, Léna JP, David P, Joly P, Lengagne T, Perrin N et al. (2011b). Consequences of genetic erosion on fitness and phenotypic plasticity in European tree frog populations (Hyla arborea). J Evol Biol 24: 99-110.
Neff BD, Pitcher TE (2005). Genetic quality and sexual selection: an integrated framework for good genes and compatible genes. Mol Ecol 14: 19-38.

Ohta T (1971). Associative overdominance caused by linked detrimental mutations. Genet Res 18: 277-286.

Ohta T, Cockerham CC (1974). Detrimental genes with partial selfing and effects on a neutral locus. Genet Res 23: 191-200.

Ouborg NJ, Pertoldi C, Loeschcke V, Bijlsma R, Hedrick PW (2010). Conservation genetics in transition to conservation genomics. Trends Genet 26: 177-187.

Pemberton J (2004). Measuring inbreeding depression in the wild: the old ways are the best. Trends Ecol Evol 19: 613-615.

Pidancier N, Miquel C, Miaud C (2003). Buccal swabs as a non-destructive tissue sampling method for DNA analysis in amphibians. Herpetol J 13: 175-178.

Primmer CR, Landry PA, Ranta E, Merila J, Piironen J, Tiira K et al. (2003). Prediction of offspring fitness based on parental genetic diversity in endangered salmonid populations. J Fish Biol 63: 909-927.

Rasanen K, Soderman F, Laurila A, Merila J (2008). Geographic variation in maternal investment: acidity affects egg size and fecundity in Rana arvalis. Ecology 89: 2553-2562.

Reed DH (2005). Relationship between population size and fitness. Conserv Biol 19 563-568.

Reed DH, Frankham R (2003). Correlation between fitness and genetic diversity. Conserv Biol 17: 230-237.

Rowe G, Beebee TJC (2003). Population on the verge of a mutational meltdown? Fitness costs of genetic load for an amphibian in the wild. Evolution 57: 177-181.

Saccheri I, Kuussaari M, Kankare M, Vikman P, Fortelius W, Hanski I (1998). Inbreeding and extinction in a butterfly metapopulation. Nature 392: 491-494.

Slate J, Pemberton J (2006). Does reduced heterozygosity depress sperm quality in wild rabbits (Oryctolagus cuniculus)? Curr Biol 16: R790-R791.

Szulkin M, Bierne N, David P (2010). Heterozygosity-fitness correlations: a time for reappraisal. Evolution 64: 1202-1217.

Tsitrone A, Rousset F, David P (2001). Heterosis, marker mutational processes and population inbreeding history. Genetics 159: 1845-1859.

Waller DM, Dole J, Bersch AJ (2008). Effects of stress and phenotypic variation on inbreeding depression in Brassica rapa. Evolution 62: 917-931.

Whitlock MC (2003). Fixation probability and time in subdivided populations. Genetics 164: 767-779.

Whitlock MC, Ingvarsson PK, Hatfield T (2000). Local drift load and the heterosis of interconnected populations. Heredity 84: 452-457.

Supplementary Information accompanies the paper on Heredity website (http://www.nature.com/hdy) 